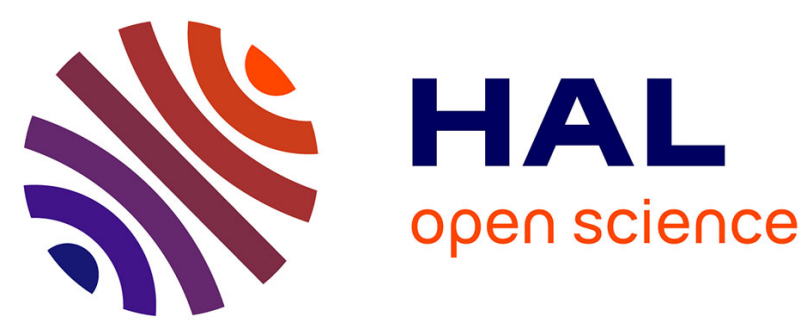

\title{
Engineered CCR5 superagonist chemokine as adjuvant in anti-tumor DNA vaccination
}

\author{
Karim Dorgham, Valérie Abadie, Mutsunori Iga, Oliver Hartley, Guy \\ Gorochov, Behazine Combadière
}

\section{- To cite this version:}

Karim Dorgham, Valérie Abadie, Mutsunori Iga, Oliver Hartley, Guy Gorochov, et al.. Engineered CCR5 superagonist chemokine as adjuvant in anti-tumor DNA vaccination. Vaccine, 2008, 26 (26), pp.3252-3260. 10.1016/j.vaccine.2008.04.003 . hal-02480557

\section{HAL Id: hal-02480557 https://hal.science/hal-02480557}

Submitted on 16 Feb 2020

HAL is a multi-disciplinary open access archive for the deposit and dissemination of scientific research documents, whether they are published or not. The documents may come from teaching and research institutions in France or abroad, or from public or private research centers.
L'archive ouverte pluridisciplinaire HAL, est destinée au dépôt et à la diffusion de documents scientifiques de niveau recherche, publiés ou non, émanant des établissements d'enseignement et de recherche français ou étrangers, des laboratoires publics ou privés. 


\title{
Engineered CCR5 superagonist chemokine as Adjuvant in anti-tumor DNA vaccination
}

\author{
Karim Dorgham $^{\dagger, \star}$, Valérie Abadie ${ }^{\dagger, *}$, Mutsunori Iga ${ }^{\dagger, \star}$, Oliver Hartley $y^{\mathbb{I I}}$, Guy Gorochov ${ }^{+, \dagger, \#, \star}$, \\ Behazine Combadière ${ }^{+, \dagger, t}$
}

\begin{abstract}
†Institut National de la Santé et de la Recherche Médicale (INSERM) U543, *Université Pierre et Marie Curie (UPMC Univ Paris 06), 91 boulevard de l’hôpital, 75634 Paris, France, "Immunologie A, Assistance Publique Hôpitaux de Paris (AP-HP) Hôpital Pitié-Salpêtrière, 83 boulevard de l'hôpital, 75634 Paris, France and "IDépartement de Biologie structurale et Bioinformatique, Centre Médical Universitaire, 1 rue Michel Servet, 1211 Geneva 4, Switzerland.
\end{abstract}

+Correspondence should be addressed to: Behazine Combadière: combadie@ @cr.jussieu.fr or to Guy Gorochov: guy.gorochov@psl.ap-hop-paris.fr

Laboratoire d'Immunologie Cellulaire, INSERM U543, UPMC Univ Paris 06, 91 bd de l'hôpital, 75634 Paris Cedex 13, France.Tel: +33140779888; Fax: +33140779734 


\begin{abstract}
Chemokine receptors are promising targets for enhancing $\mathrm{T}$ cell immunity and anti-cancer therapy. CCL5 is a potential adjuvant for DNA vaccination. We postulated that CCR5 superagonists could be even more effective. A CCR5 superagonist derived from natural CCL5 by directed in vitro evolution, namely 1P7, is used as a DNA vaccine adjuvant and expressed as fused chemokine-Ig (1P7-Ig). We show that OVA+1P7-Ig DNA co-inoculation induced higher frequencies of OVAspecific CD8 lymphocytes than OVA+CCL5-Ig or controls and gave an even better protection against tumor growth in a CCR5-dependant manner. Our results indicate that CCR5-superagonists may provide potent adjuvants for vaccines.
\end{abstract}

Key words: CCR5 superagonist, DNA vaccine, genetic adjuvant, tumor vaccine.

Abbreviations: APC, antigen presenting cell; OVA, Ovalbumin; DC, dendritic cell; CCL, CC chemokine ligand; CCR, CC chemokine receptor 


\section{Introduction}

CCL5 is a small 68 amino acids protein produced predominantly by CD8+ T-cells, epithelial cells, fibroblasts and platelets [1]. Besides its role in facilitating the deployment of antigen-presenting cells (APC) and immune cells (NK, B- or T-cells), CCL5 is clearly associated with Th1-type cellular responses $[2,3]$. Therefore, CCL5 plays a key role in the induction of adaptive immune responses [4]. In humans, the presence of intratumoral $\mathrm{T}$ cells correlates with improved clinical outcome in advanced ovarian carcinoma [5] and in colorectal cancer [6, 7]. Accumulating evidence in mice [8-10] and in humans $[5,6,11]$ suggests that this protective anti-cancer response is mediated in part by effector T cells and long-lived memory T cells [7]. Thus, improvement of the intensity of the effector and memory $\mathrm{T}$ cell response might have an important impact in the control of tumor growth.

DNA vaccination is an attractive approach for cancer immunotherapy $[12,13]$, however one major drawback is its limited potency. We and others have shown that plasmid-encoded cytokines, chemokines, or co-stimulatory molecules are promising DNA vaccine adjuvants against viral infections [14-17]. Similar approachs using chemokines such as CCL19 and CCL21 as adjuvant for DNA vaccination have been also proposed to enhance anti-tumor immunity [18-20]. In a preventive DNA vaccination model, we have recently shown that CX3CL1-Ig can enhance tumorantigen specific T cell priming after a single DNA injection and protect against tumor growth [17]. In addition, in a therapeutic tumor model when the tumor is installed, intratumoral DNA injection coding CCL5-Ig reduces tumor growth, based on intra-tumoral recruitment of immune cells (DC, NK, CD4 and CD8 cells) in both an antigen-specific and non-specific manner suggesting the involvement of both adaptive and innate immunity [21]. Previous studies have explored the use of CCL5 as a genetic adjuvant for DNA vaccines that encode antigens derived from various pathogens such as HIV-1 [22, 23], HPV [24] or HSV [25] in preventive vaccination, however several DNA 
injections are necessary for vaccine efficacy. These studies all showed that exogenous CCL5 is effective in amplifying the adaptive branch of the immune response to DNA vaccines, as documented by enhancement of Ag-specific T helper cell proliferative or CTL responses, and increased Th1 cytokine (IFN-gamma and TNF-alpha) production. CCL5 induces leukocyte migration by binding to specific receptors in the seven-transmembrane G-protein coupled receptor family, CCR1 [26], CCR3 [27] and CCR5 [28]. CCL5 influences the trafficking of both T-cells prevalently associated with Th1 responses [29] and of effector T cells [30, 31]. It also acts on a range of other cells, including basophils, eosinophils, natural killer (NK) cells, monocytes, dendritic cells (DCs) and mast cells [32]. CCL5 production is induced by the combination of Th1 type cytokines (TNF-alpha, IFN-gamma) and inhibited by Th2 type cytokines (IL4 and IL13) [33]. At this stage, we postulated that mutant chemokine that behave as CCR5 superagonists might be even more effective than wild type CCL5 at amplifying the adaptive immune response.

We have previously reported the construction of phage chemokine libraries and the identification of CCL5 analogues with increased capacity to engage CCR5, including a superagonist [34]. Subsequent work using this approach led us to identify a new mutant; 1P7. The present work described for the first time a new CCR5 superagonist and its potential efficacy in DNA vaccination. We designed a 1P7-immunoglobulin (1P7-Ig) expression plasmid to be co-inoculated with the antitumor DNA vaccine based on our previous work [17]. The chemokine-Ig fusion was used because it presents the advantages of divalent affinity, non cytolytic effect and long in vivo half-life with conserved activity of both proteins $[21,35]$. Here, we show that compared to Ig fused to wild type CCL5, 1P7-Ig significantly enhanced effector CD8 T cell anti-tumor response. 
2. Materials and Methods

\subsection{Mice, cell lines and chemokines}

Wild-type C57BL/6 mice were purchased from Elevage Janvier (Le Genest, Saint Isle, France) and C57BL/6 CCR5 -/- mice from Jackson Laboratories (Charles River, Saint-Aubin les Elbeufs, France). All mice were females of 6 to 10 weeks old. All experiment protocols were approved by the local animal experimentation and ethics committee guidelines.

Tumor cell lines derived from C57BL/6 mice were obtained from the American Type Culture Collection (ATCC, Rockville, MD, USA). The H-2b lymphoma EL4 and its derivative E.G7-OVA, which expresses chicken ovalbumin (OVA), were maintained as described previously [21]. CHOCCR5, HEK-CCR5, HEK-CCR1, HEK-CCR3 and HeLa-CD4-LTRLacZ cells stably expressing CCR5 (HeLa-P5L) have been described previously [34]. CCL5 analogues proteins were prepared by total chemical synthesis, as described elsewhere [36] and amino acid sequences are presented in Table 1.

\subsection{Calcium Mobilization Assay}

Experiments were carried out essentially as in [34] using a FLEX-station machine (Molecular Devices, CA, USA). Hela-P5L cells, HEK-CCR1 or HEK-CCR3 cells were loaded with Fluo-4 (Invitrogen, Molecular Probes, France) according to the manufacturer's recommendations and maintained at $37^{\circ} \mathrm{C}$. Peak signals were defined as the area under the trace (Calculated using SoftMax Pro software (Molecular Devices) and expressed in relative fluorescence units) during a 45 second period following chemokine addition. Determinations were performed in duplicate and dose-curves were fitted using Prism software (Graphpad Software, San Diego, CA, USA). 


\subsection{CCR5 receptor down-modulation experiments}

HEK-CCR5 cells $\left(10^{5}\right)$ were incubated for $30 \mathrm{~min}$ at $37^{\circ} \mathrm{C}$ in supplemented culture medium containing various concentrations (0 to $100 \mathrm{nM}$ ) of chemokines. Medium alone was used for controls. Cells were washed 5 times with cold PBS and incubated for 30 min on ice with $0.5 \mu \mathrm{g}$ of anti-CCR5 mAb (clone 2D7 phycoerythrin-conjugated, PharMingen, France). Cells were washed two times, fixed with $4 \%$ paraformaldehyde, and analyzed with a FACScalibur using Cell Quest software (Becton Dickinson, San Diego, CA, USA). At least 10,000 events were accumulated for each sample.

\subsection{Competitive radio-ligand binding on CCR5}

Experiments were performed as in [37]. CHO-CCR5 cells were seeded into 24 well plates (1.2 $\mathrm{x}$ $10^{5}$ cells/well). After overnight incubation, competition binding was performed on whole cells for $3 \mathrm{~h}$ at $4^{\circ} \mathrm{C}$ using $12 \mathrm{pM}$ radiolabeled CCL3 (Amersham, France) plus variable amounts of unlabelled ligand. Determinations were made in quadruplicate and $\mathrm{IC}_{50}$ values were derived from monophasic concentration inhibition curves fitted using Prism software.

\subsection{Plasmid construction}

Expression vector coding chicken ovalbumin (OVA) was prepared as previously described. Briefly, OVA ORF encoding amino acids 1-386 (GeneBank \# J00895) was prepared by polymerase chain reaction (PCR) from cell line E.G7-OVA cDNA and subcloned into the plasmid vector pVRC (kindly provided by Dr. Barouch,; Division of Viral Pathogenesis, Beth, Israel Deaconess Medical Center, Harvard Medical School, Boston, MA, USA). The chimeric CCL5-Ig expression vector used was as previously described [21]. As with the CCL5-Ig construct, we used the Fc $\gamma 2$ a fragment 
mutated in the Clq binding motif (E318, K320, K322) and the FcyRI binding site (L235) to produce a noncytolytic form of 1P7-Ig [14, 35]. The 1P7 DNA sequence was amplified from the phage display vector using a specific upstream primer encoding the human CCL5 signal peptide 5' -TTT CTG CAG ATG AAG GTC TCC GCG GCA CGC CTC GCT GTC ATC CTC ATT GCT ACT GCC CTC TGC GCT CCT GCA TCT GCC ATG TCC CCA CTG TCC-3' (the recognition site for $P s t I$ is underlined) and a downstream primer 5' -CAA CTC TTT GGA GAT GTC TAG AGG GGC CCC A-3' (the recognition sites for XbaI and PspOMI - in that order- are underlined). The product was cut with $P s t I$ and $P s p O M I$ and inserted into pVRC that had been linearized using PstI and NotI. The ligated DNA was electroporated into E. coli TG1 and DNA inserts of selected clones were sequenced using an automatic sequencer ABI 377 (Perkin Elmer, USA). All plasmids were produced by Tebu-Biolab (Tebu, France) in endotoxin-free conditions.

\subsection{DNA vaccination and mice immunomonitoring}

Three groups of mice were immunized intramuscularly by co-administration of $100 \mu \mathrm{g}$ OVA plasmid DNA and $100 \mu \mathrm{g}$ of one of the following: Ig plasmid DNA, CCL5-Ig plasmid DNA or 1P7-Ig plasmid DNA. Blood samples were collected in RPMI 1640 containing $40 \mathrm{U} / \mathrm{ml}$ heparin by retro-orbital puncture before each immunization (day 0) and on day 15. Previous experiments showed that day 15 is the peak of OVA-specific T cell detection in blood after DNA immunization [17]. Following red blood cells lysis, cell suspensions were stained with PE-conjugated H-

2Kb/OVA 257-264 (SIINFEKL) tetramer (Proimmune Oxford, UK) and anti-CD8-APC monoclonal antibody (clone Ly-2; Becton Dickinson, France). Samples were washed, fixed and ten thousand CD8 events were analyzed by flow cytometry with CellQuest ${ }^{\mathrm{TM}}$ software. 


\subsection{Tumor challenge}

Three groups of mice were injected subcutaneously in the right flank with $2 \times 10^{4}$ tumor cells in 100 $\mu \mathrm{l}$ PBS. Tumor size was measured three times a week with a caliper, and the tumor volume was estimated from the following formula: width $\mathrm{x}$ length $\mathrm{x}$ (width + length)/2.

\subsection{In vivo cytotoxic T cell assay}

Detection of in vivo cytotoxic T lymphocytes (CTL) was performed as described previously [38]. Splenocytes were prepared from naïve animals by passing through sterile meshes. Erythrocytes were removed using red-blood cells lysis buffer for five minutes followed by three washes in PBS $1 \mathrm{X}$ and resuspending at $5 \times 10^{6}$ cells $/ \mathrm{ml}$. Cells were divided into two populations, one of which was pulsed with $1 \mu \mathrm{g} / \mathrm{ml}$ of SIINFEKL (MHC-Class I restricted peptide) for $90 \mathrm{~min}$ at $37^{\circ} \mathrm{C}$. Cells were then washed and labeled with CFSE (Molecular Probes, Eugene, OR) for 15 min at $37^{\circ} \mathrm{C}$. Peptidepulsed cells were labeled with $5 \mu \mathrm{M}$ of $\mathrm{CFSE}\left(\mathrm{CFSE}^{\text {high }}\right)$ and unpulsed cells with $0.5 \mu \mathrm{M}\left(\mathrm{CFSE}^{\text {low }}\right)$. Cells were then washed once in PBS-2\% FCS and twice in PBS 1X prior to intravenous injection into recipient mice. Cells were recovered $20 \mathrm{~h}$ after transfer for flow cytometric analysis using CellQuest software (Becton Dickinson Immunocytometry Systems, san José, CA). One million live events were acquired for further CFSE analysis.

\subsection{Data analysis}

Statistical analysis for comparison of two groups of mice were performed using the unpaired Student's $t$-test and Graphpad software. Data handling and presentation were performed using Prism4.0 software. Probability values $(\mathrm{P})<0.05$ were considered significant. 
3. Results

\subsection{Chemokine variant $1 P 7$ is a CCR5 superagonist.}

In a preliminary screen of a panel of CCL5 mutants isolated from our earlier phage display work on CCR5 [34], 1P7 was identified as a strong CCR5 agonist. Comparison with native CCL5 shows 1P7 to be a CCR5 superagonist, giving a maximum response $\left(E_{\max }\right)$ at $170 \%$ of that of CCL5, and capable of eliciting CCR5 signaling at concentrations where CCL5 gives no detectable signal (Fig 1A). We then compared the capacity of 1P7 with that of the native CCL5 to elicit CCR5 downregulation. Under the assay conditions used, 1P7 induced significant dose-dependent downmodulation of CCR5 with a response at $1 \mathrm{nM}$ compared to that of $100 \mathrm{nM}$ CCL5 (Fig 1B). These observations are in agreement with our previous work, which showed that CCR5 down-modulation is closely linked with receptor activation [34]. The increased signaling activity is not a consequence of an increased CCR5 binding affinity, since in competitive binding assays on CCR5, both 1P7 and CCL5 have similar IC 50 values $(0.74 \mathrm{nM}$ for $1 \mathrm{P} 7$, compared to $2.9 \mathrm{nM}$ and $1.56 \mathrm{nM}$ for CCL5 and CCL3, respectively) (Fig 1C). Finally, as expected the native chemokine CCL5 exhibited strong agonist activity on CCR1 and CCR3 while 1P7 behaved as a very weak partial agonist for CCR1 (Fig 1D, upper panel) and induced a weak calcium signal on CCR3 (Fig 1D, lower panel). Taking account of its superagonist activity on CCR5 and its increased CCR5 selectivity with respect to CCL3 and CCL5, we elected to carry out further work on 1P7 to evaluate its efficacy to induce anti-tumor T cell immunity (Fig 2).

\subsection{P7-Ig DNA enhances the tumor-specific CD8 cellular response.}

CCL5 has been previously reported as an adjuvant in DNA vaccination [22-25]. To compare the adjuvant effect of CCL5-Ig and 1P7-Ig, we co-administered chemokine-Ig plasmids with or 
without OVA plasmid by intramuscular route in C57BL/6 mice. In C57BL/6 mice, OVA 257-264 (SIINFEKL) is the immunodominant ovalbumin determinant recognized in the context of $\mathrm{H}-2 \mathrm{~K}^{\mathrm{b}}$ [39]. We evaluated the effect of chemokine adjuvants on the amplitude of the OVA-specific CD8+ T cell response by tetramer $\mathrm{H}-2 \mathrm{~K}^{\mathrm{b}} / \mathrm{OVA} 257-264$ staining on peripheral blood cells at day 15 , the peak of the cellular immune response [17]. H-2K /OVA 257-264-specific CD8+ cells were significantly increased following administration of 1P7-Ig DNA (P < 0.0001) and CCL5-Ig DNA $(\mathrm{P}=0.0003)$ compared to DNA Ig control group, only when co-administrated with OVA DNA (Fig 3A and 3B). More importantly, both the percentage of responder mice and intensity of the antigen-specific CD8 T cell response were significantly increased in the DNA 1P7-Ig group (1.680 $\pm 0.244 \%, \mathrm{n}=32)$ compared to the wild-type CCL5-Ig group $(0.972 \pm 0.148 \%, \mathrm{n}=29, \mathrm{P}=0.0187)$ or the Ig control group $(0.374 \pm 0.050 \%, \mathrm{n}=30, \mathrm{P}<0.0001)$ with $63 \%, 41 \%$ and $7 \%$ of responders, respectively (Fig. 3B). We also observed more OVA-specific T cells in the CCL5-Ig group mice than in the Ig control group mice $(\mathrm{P}=0.003)$ (Fig 3B). However, control groups that received Ig, CCL5-Ig or 1P7-Ig plasmids alone showed an absence of OVA-specific CD8 T cells demonstrating an increase of cellular immunity to OVA antigen in the presence of chemokine-Ig. Phenotypic and cytokine analysis have shown that all OVA-specific CD8 T cells generated, displayed a CD44 ${ }^{\text {high }} \mathrm{CD} 62 \mathrm{~L}^{\text {low }}$ phenotype, a fraction of which also produced IFN-gamma (data not shown). Taken together, these observations suggest that these cells are antigen-specific effector T cells that were primed in vivo.

In addition to CCR5, CCL5 binds and activates at least 2 chemokine receptors: CCR1 [26] and CCR3 [27]. Given that CCR5 is the CCL5 receptor primarily expressed on lymphoid cells and that 1P7 shows enhanced selectivity towards CCR5 and less toward CCR3, we tested the 1P7-Ig adjuvant effect in CCR5 KO mice after co-administration of DNA coding for OVA and chemokineIg (Fig 3B). Controlled experiments showed that CCR5 KO mice and C57/BL6 mice have similar 
capacity to generate OVA-specific CD8 T cell responses after OVA protein + CFA or recombinant OVA-MVA (Modified Ankara Vaccinia virus) (Data not shown). However, the capacity of both CCL5-Ig and 1P7-Ig DNA to amplify OVA-specific CD8 cells was completely lost in CCR5 deficient mice (Fig 3B), underlining the importance of CCR5 activation in the adjuvant effect mediated by CCL5 and its analogues.

We conclude that DNA 1P7-Ig is significantly more efficient at enhancing antigen-specific CD8+ T cell immune responses to a DNA vaccine than wild-type CCL5-Ig.

\subsection{Co-vaccination based on OVA and 1P7-Ig confers optimal protection against tumor challenge.}

Prior to tumor challenge, we evaluated the in vivo cytotoxic activity of induced-T cells after DNA vaccination in mice by adoptive transfer of CFSE labeled target cells pulsed or unpulsed with the OVA peptide SIINFEKL. As depicted in Fig 4, a significant increase in cytotoxic activity was observed in mice that received both OVA DNA and chemokine-Ig DNA compared to control groups. This result demonstrates once more antigen-specific $\mathrm{T}$ cell responses after DNA vaccination with CCL5 variants. Even though, DNA vaccination with 1P7 might induce a slightly higher cytotoxic activity, no significant differences were observed between CCL5-Ig and 1P7-Ig co-injected with OVA.

In order to test whether the enhanced frequency of antigen-specific CD8 $\mathrm{T}$ cell responses obtained using 1P7-Ig as an adjuvant can contribute significantly to control of tumor growth compared to CCL5-Ig adjuvant, OVA-vaccinated mice were challenged with E.G7-OVA tumor cells and monitored for OVA-specific T cell responses and in vivo tumor growth. On day 0, C57BL/6 mice were injected with DNA encoding OVA and CCL5-Ig $(n=23)$, OVA and 1P7-Ig $(n=24)$ or OVA and $\operatorname{Ig}(\mathrm{n}=24)$. As shown above, we found significantly more OVA-specific CD8 T cells in the DNA 1P7-Ig group than in the Ig group $(1.67 \pm 0.35 \%$ and $0.51 \pm 0.09 \%$, respectively, $\mathrm{P}=0.0063$, 
data not shown) at day 15 . On day 30, mice were challenged with either E.G7-OVA tumor cells or EL4. Kinetics of tumor growth and percentage of mice bearing tumors are shown in Fig 5A and 5B. No significant differences were observed in the tumor size between the $\operatorname{Ig}\left(5604 \pm 1901 \mathrm{~mm}^{3}\right)$ and CCL5-Ig $\left(4361 \pm 2001 \mathrm{~mm}^{3}\right)$ DNA vaccinated groups while the mean E.G7-OVA tumor size was strongly reduced in 1P7-Ig group $\left(1585 \pm 365 \mathrm{~mm}^{3}, \mathrm{P}=0.032\right)$ compared to the Ig control group (Fig 5A). However, a similar size of EL4 tumor was observed in all groups (Fig 5B) demonstrating that tumor evolution is controlled by an antigen-dependant mechanism.

We also depicted in Fig 5C, the percentage of vaccinated mice that did not develop a tumor. A significantly higher number of tumor-free mice was observed in the 1P7-Ig group (85\% tumor free mice, $\mathrm{P}=0.01)$ and CCL5-Ig vaccinated mice $(77 \%$ tumor-free mice, $\mathrm{P}=0.05)$ compared to $\mathrm{Ig}$ group (43\% tumor-free mice) (Fig. 5C). Finally, we found a positive correlation between OVA 257-264-specific CD8 T cell counts and tumor size ( $<<0.05)$. Significantly fewer OVA-specific cells were evident in tumor-bearing mice $(n=13)$ than in tumor-free mice $(n=28)(0.34 \pm 0.05 \%$ and $1.40 \pm 0.21 \%$ anti-OVA CD8 cells, respectively, $\mathrm{P}=0.004)$ (Fig. 5D). This data reinforces the major role of $\mathrm{T}$ cells in the control of E.G7- OVA tumor growth.

In conclusion, these results confirm that 1P7, a CCR5 superagonist, acts as an effective DNAencoded adjuvant, showing enhanced efficacy in terms of the level of induction of a specific CD8 T cell response, which can better control tumor development in mice than CCL5, the native CCR5 agonist. 


\section{Discussion}

Upon antigenic stimulation, establishment of the adaptive immune responses that determines vaccine efficacy is dependent on efficient T cell priming. In this report we have identified, in 1P7, a new CCL5 mutant that functions as a CCR5 superagonist with an increased CCR5 selectivity compared to native CCL5. When presented on immunoglobulin as a dimer (1P7-Ig) and used in a DNA vaccination strategy, the mutant protein provided a potent adjuvant effect with a strong in vivo antigen-specific $\mathrm{T}$ cell expansion that was efficient enough to protect against an antigenexpressing tumor challenge. Our observation that $1 \mathrm{P} 7$ is a selective CCR5 superagonist is in accordance with the complete elimination of the adjuvant effect when 1P7-Ig was used in CCR5deficient mice.

The level of immunogenicity induced by tumor antigens is usually insufficient to elicit strong and efficient immune responses. To compensate for the low level of $\mathrm{T}$ cell proliferation, both exogenous administration of cytokines such as IL-2, IL-7 and IL-15 and multiple injections have been proposed to positively regulate effector T-cell survival and proliferation [40]. Similarly, several chemokines such as GM-CSF, CCL5, CCL4, CCL3 as well as Flt3-ligand and other cytokines have been studied in various DNA vaccination strategies [25, 40-48]. This type of adjuvant strategy is also applicable to DNA vaccination: co-administration of plasmid-encoded immunogens and plasmid-encoded CCL5 resulted in augmentation of antigen-specific T helper cell-proliferative responses and Th1 cytokine production such as IFN-gamma [22, 23, 49]. The effect of these strategies on the enhancement of effector $\mathrm{T}$ cell responses remained partial however, and we speculated that efficacy could be improved by using a CCR5 superagonist instead of native CCL5. This turned out to be the case. In our tumor challenge model, when the vaccine antigen is expressed in the tumor (E.G7-OVA) a significant reduction in tumor size was apparent in mice 
receiving 1P7-Ig DNA, but not in mice receiving CCL5-Ig. In addition, in vivo induced antigenspecific $\mathrm{T}$ cells displayed cytotoxic activities. These results strongly argue in favor of a CTLmediated protection and against a direct anti-cancer effect of CCL5 as proposed previously by our group [21]. While CCR5 agonists based on CCL5 have been successfully used as anti-HIV agents [34, 37, 50, 51], our study provides the first evidence that CCR5 agonists may also function as effective adjuvants in vaccine strategies.

DNA vaccine delivery systems can mimic the antigenicity of infectious organisms and have become a growing field in vaccine technology. DNA vaccine effectively engages both MHC-class I and MHC-class II pathways allowing induction of CD8 and CD4 T cell immune responses [52]. Even though DNA is considered to be a good vector for T cell priming, it remains insufficient to elicit strong immune responses [53]. To compensate for the low level of T cell proliferation, both exogenous administrations of cytokines such as IL-2, IL-7 and IL-15 and multiple injection, as well as an additional use of "boost" vector [54] have been proposed to positively regulate effector Tcell survival and proliferation $[40,41]$. We propose $1 \mathrm{P} 7$ to be considered as a potent potential adjuvant in DNA vaccination. It has to be noted that in our work, single DNA vaccination was sufficient to induce a high level of control of tumor growth, while most DNA vaccination studies necessitate multiple DNA vaccination. In addition, 1P7 was used under the form of a DNA adjuvant and not as purified protein and thus cannot yet be compared to chemically modified chemokines [37].

How might CCR5 superagonists boost immune responses is still under investigation. Firstly, immature DCs exhibit potent chemotaxis in response to CCL5 [55], hence CCR5 activation may be an effective means by which to recruit antigen-sampling cells to the site of immunization. Secondly, following Ag-induced cell differentiation, Th1 CD4 T cells as well as memory and effector CD8 T cells express CCR5 [56, 57]. According to a recent study [58], CCR5 expression 
by T cells would not only be important for maintaining T cell-APC interactions, but CCR5 agonists could also act as a costimulator. We therefore suggest that 1P7 (and possibly APC-bound 1P7) could directly enhance T cell priming and activation in the lymph nodes. Thirdly, a number of other CCR5-expressing cell types, including NKs, monocytes and macrophages may also contribute to the antigen-specific $\mathrm{T}$ cell response. CCR5 has also been identified as a receptor that selectively triggers IL-12 production by the CD8+ subset of DCs [59]. Finally, CCL5 plays a key role in the migration of effector cells from lymphoid organs to inflammatory sites. In our previous work [21], we injected DNA-CCL5 into installed solid tumor, either EL4 or E.G7-OVA. In both types of tumor, CCL5-Ig DNA injection or CCL5 expression induced tumor reduction suggesting an involvement of both adaptive and innate immunity, consequently CCL5-Ig was proposed for a therapeutic vaccination strategy. In this manuscript, we focused on preventive tumor vaccination and demonstrated that DNA 1P7-Ig + DNA coding for a tumor antigen (OVA) enhanced the frequency of tumor-specific $\mathrm{T}$ lymphocytes that were able to control tumor growth, thus demonstrating in this model a major role of 1P7-Ig for a preventive vaccination strategy. Therefore, CCR5 superagonists could modulate upstream as well as downstream events of the anti-tumor response. Further investigation using strategies based on either CCR5 superagonists such as 1P7 or CCR5 antagonists such as P1 [34] may help to further elucidate the role of CCR5 in the regulation of cellular immune responses. 
Acknowledgements: This work was supported by the French "Agence Nationale de Recherche" (ANR “jeunes chercheurs" JC05-4645) and Cancéropole Ile-de-France to B.C., the Swiss National Science Foundation (3100A0-11042, O.H.), and the European FP6 "INNOCHEM" and “ATTACK” (Contract: LSHC-CT-2005-018914) programs (G.G.). M.I. was a fellowship recipient of SIDACTION, Paris. 


\section{References}

[1] Taub DD, Oppenheim JJ. Chemokines, inflammation and the immune system. Ther Immunol 1994;1(4):229-46.

[2] Sallusto F, Mackay CR, Lanzavecchia A. The role of chemokine receptors in primary, effector, and memory immune responses. Annu Rev Immunol 2000;18:593-620.

[3] Luther SA, Cyster JG. Chemokines as regulators of T cell differentiation. Nat Immunol 2001;2(2):102-7.

[4] Esche C, Stellato C, Beck LA. Chemokines: key players in innate and adaptive immunity. J Invest Dermatol 2005;125(4):615-28.

[5] Zhang L, Conejo-Garcia JR, Katsaros D, Gimotty PA, Massobrio M, Regnani G, et al. Intratumoral $\mathrm{T}$ cells, recurrence, and survival in epithelial ovarian cancer. $\mathrm{N}$ Engl $\mathrm{J}$ Med 2003;348(3):203-13.

[6] Pages F, Berger A, Camus M, Sanchez-Cabo F, Costes A, Molidor R, et al. Effector memory $\mathrm{T}$ cells, early metastasis, and survival in colorectal cancer. $\mathrm{N}$ Engl $\mathrm{J}$ Med 2005;353(25):2654-66.

[7] Musha H, Ohtani H, Mizoi T, Kinouchi M, Nakayama T, Shiiba K, et al. Selective infiltration of CCR5(+)CXCR3(+) T lymphocytes in human colorectal carcinoma. Int J Cancer 2005;116(6):949-56.

[8] Kirk CJ, Hartigan-O'Connor D, Mule JJ. The dynamics of the T-cell antitumor response: chemokine-secreting dendritic cells can prime tumor-reactive $\mathrm{T}$ cells extranodally. Cancer Res 2001;61(24):8794-802.

[9] Kim CH, Hong MJ, Park SD, Kim CK, Park MY, Sohn HJ, et al. Enhancement of antitumor immunity specific to murine glioma by vaccination with tumor cell lysate-pulsed dendritic cells engineered to produce interleukin-12. Cancer Immunol Immunother 2006:1-11.

[10] Wang LX, Li R, Yang G, Lim M, O'Hara A, Chu Y, et al. Interleukin-7-dependent expansion and persistence of melanoma-specific $\mathrm{T}$ cells in lymphodepleted mice lead to tumor regression and editing. Cancer Res 2005;65(22):10569-77.

[11] Ribas A. Clinical trials with tumor antigen genetically modified dendritic cells. Semin Oncol 2005;32(6):556-62. 
[12] Pavlenko M, Leder C, Pisa P. Plasmid DNA vaccines against cancer: cytotoxic Tlymphocyte induction against tumor antigens. Expert Rev Vaccines 2005;4(3):315-27.

[13] Lowe DB, Shearer MH, Kennedy RC. DNA vaccines: successes and limitations in cancer and infectious disease. J Cell Biochem 2006;98(2):235-42.

[14] Barouch DH, Santra S, Steenbeke TD, Zheng XX, Perry HC, Davies ME, et al. Augmentation and suppression of immune responses to an HIV-1 DNA vaccine by plasmid cytokine/Ig administration. J Immunol 1998;161(4):1875-82.

[15] Barouch DH, Craiu A, Kuroda MJ, Schmitz JE, Zheng XX, Santra S, et al. Augmentation of immune responses to HIV-1 and simian immunodeficiency virus DNA vaccines by IL-2/Ig plasmid administration in rhesus monkeys. Proc Natl Acad Sci U S A 2000;97(8):4192-7.

[16] Barouch DH, McKay PF, Sumida SM, Santra S, Jackson SS, Gorgone DA, et al. Plasmid chemokines and colony-stimulating factors enhance the immunogenicity of DNA priming-viral vector boosting human immunodeficiency virus type 1 vaccines. J Virol 2003;77(16):8729-35.

[17] Iga M, Boissonnas A, Mahe B, Bonduelle O, Combadiere C, Combadiere B. Single CX3CL1-Ig DNA administration enhances T cell priming in vivo. Vaccine 2007.

[18] Westermann J, Nguyen-Hoai T, Baldenhofer G, Hopken UE, Lipp M, Dorken B, et al. CCL19 (ELC) as an adjuvant for DNA vaccination: induction of a TH1-type T-cell response and enhancement of antitumor immunity. Cancer Gene Ther 2007;14(6):523-32.

[19] Elzaouk L, Pavlovic J, Moelling K. Analysis of antitumor activity elicited by vaccination with combinations of interleukin-12 DNA with gp100 DNA or the chemokine CCL21 in vivo. Hum Gene Ther 2006;17(8):859-70.

[20] Yamano T, Kaneda Y, Hiramatsu SH, Huang S, Tran AN, Giuliano AE, et al. Immunity against breast cancer by TERT DNA vaccine primed with chemokine CCL21. Cancer Gene Ther 2007;14(5):451-9.

[21] Lavergne E, Combadiere C, Iga M, Boissonnas A, Bonduelle O, Maho M, et al. Intratumoral CC chemokine ligand 5 overexpression delays tumor growth and increases tumor cell infiltration. J Immunol 2004;173(6):3755-62.

[22] Kim JJ, Nottingham LK, Sin JI, Tsai A, Morrison L, Oh J, et al. CD8 positive T cells influence antigen-specific immune responses through the expression of chemokines. J Clin Invest 1998;102(6):1112-24. 
[23] Xin KQ, Lu Y, Hamajima K, Fukushima J, Yang J, Inamura K, et al. Immunization of RANTES expression plasmid with a DNA vaccine enhances HIV-1-specific immunity. Clin Immunol 1999;92(1):90-6.

[24] Kim SJ, Lee C, Lee SY, Kim I, Park JS, Sasagawa T, et al. Enhanced immunogenicity of human papillomavirus $16 \mathrm{~L} 1$ genetic vaccines fused to an ER-targeting secretory signal peptide and RANTES. Gene Ther 2003;10(15):1268-73.

[25] Sin J, Kim JJ, Pachuk C, Satishchandran C, Weiner DB. DNA vaccines encoding interleukin-8 and RANTES enhance antigen-specific Th1-type CD4(+) T-cell-mediated protective immunity against herpes simplex virus type 2 in vivo. J Virol 2000;74(23):11173-80.

[26] Schall TJ, Bacon K, Toy KJ, Goeddel DV. Selective attraction of monocytes and T lymphocytes of the memory phenotype by cytokine RANTES. Nature 1990;347(6294):669-71.

[27] Kitaura M, Nakajima T, Imai T, Harada S, Combadiere C, Tiffany HL, et al. Molecular cloning of human eotaxin, an eosinophil-selective CC chemokine, and identification of a specific eosinophil eotaxin receptor, CC chemokine receptor 3. J Biol Chem 1996;271(13):7725-30.

[28] Combadiere C, Ahuja SK, Tiffany HL, Murphy PM. Cloning and functional expression of CC CKR5, a human monocyte CC chemokine receptor selective for MIP-1(alpha), MIP-1(beta), and RANTES. J Leukoc Biol 1996;60(1):147-52.

[29] Sallusto F, Lenig D, Mackay CR, Lanzavecchia A. Flexible programs of chemokine receptor expression on human polarized $\mathrm{T}$ helper 1 and 2 lymphocytes. $\mathrm{J}$ Exp Med 1998;187(6):875-83.

[30] Kim CH, Nagata K, Butcher EC. Dendritic cells support sequential reprogramming of chemoattractant receptor profiles during naive to effector $\mathrm{T}$ cell differentiation. $\mathrm{J}$ Immunol 2003;171(1):152-8.

[31] Boissonnas A, Combadiere C, Lavergne E, Maho M, Blanc C, Debre P, et al. Antigen distribution drives programmed antitumor CD8 cell migration and determines its efficiency. J Immunol 2004;173(1):222-9.

[32] Sozzani S, Locati M, Allavena P, Van Damme J, Mantovani A. Chemokines: a superfamily of chemotactic cytokines. Int J Clin Lab Res 1996;26(2):69-82.

[33] Devergne O, Marfaing-Koka A, Schall TJ, Leger-Ravet MB, Sadick M, Peuchmaur M, et al. Production of the RANTES chemokine in delayed-type hypersensitivity reactions: involvement of macrophages and endothelial cells. J Exp Med 1994;179(5):1689-94. 
[34] Hartley O, Dorgham K, Perez-Bercoff D, Cerini F, Heimann A, Gaertner H, et al. Human immunodeficiency virus type 1 entry inhibitors selected on living cells from a library of phage chemokines. J Virol 2003;77(12):6637-44.

[35] Zheng XX, Steele AW, Nickerson PW, Steurer W, Steiger J, Strom TB. Administration of noncytolytic IL-10/Fc in murine models of lipopolysaccharide-induced septic shock and allogeneic islet transplantation. J Immunol 1995;154(10):5590-600.

[36] Wilken J, Hoover D, Thompson DA, Barlow PN, McSparron H, Picard L, et al. Total chemical synthesis and high-resolution crystal structure of the potent anti-HIV protein AOPRANTES. Chem Biol 1999;6(1):43-51.

[37] Hartley O, Gaertner H, Wilken J, Thompson D, Fish R, Ramos A, et al. Medicinal chemistry applied to a synthetic protein: development of highly potent HIV entry inhibitors. Proc Natl Acad Sci U S A 2004;101(47):16460-5.

[38] Marzo AL, Kinnear BF, Lake RA, Frelinger JJ, Collins EJ, Robinson BW, et al. Tumorspecific CD4+ T cells have a major "post-licensing" role in CTL mediated anti-tumor immunity. $\mathrm{J}$ Immunol 2000;165(11):6047-55.

[39] Rotzschke O, Falk K, Stevanovic S, Jung G, Walden P, Rammensee HG. Exact prediction of a natural T cell epitope. Eur J Immunol 1991;21(11):2891-4.

[40] Barouch DH, Letvin NL. Cytokine-induced augmentation of DNA vaccine-elicited SIVspecific immunity in rhesus monkeys. Dev Biol (Basel) 2000;104:85-92.

[41] Westermann J, Nguyen-Hoai T, Mollweide A, Richter G, Schmetzer O, Kim HJ, et al. Flt3 ligand as adjuvant for DNA vaccination augments immune responses but does not skew TH1/TH2 polarization. Gene Ther 2004.

[42] Biragyn A, Tani K, Grimm MC, Weeks S, Kwak LW. Genetic fusion of chemokines to a self tumor antigen induces protective, T-cell dependent antitumor immunity. Nat Biotechnol 1999;17(3):253-8.

[43] Sin JI, Kim JJ, Arnold RL, Shroff KE, McCallus D, Pachuk C, et al. IL-12 gene as a DNA vaccine adjuvant in a herpes mouse model: IL-12 enhances Th1-type CD4+ T cell-mediated protective immunity against herpes simplex virus-2 challenge. J Immunol 1999;162(5):2912-21.

[44] Kusakabe K, Xin KQ, Katoh H, Sumino K, Hagiwara E, Kawamoto S, et al. The timing of GM-CSF expression plasmid administration influences the Th1/Th2 response induced by an HIV1-specific DNA vaccine. J Immunol 2000;164(6):3102-11. 
[45] Eo SK, Kumaraguru U, Rouse BT. Plasmid DNA encoding CCR7 ligands compensate for dysfunctional CD8+ T cell responses by effects on dendritic cells. J Immunol 2001;167(7):35929.

[46] Baek KM, Ko SY, Lee M, Lee JS, Kim JO, Ko HJ, et al. Comparative analysis of effects of cytokine gene adjuvants on DNA vaccination against Mycobacterium tuberculosis heat shock protein 65. Vaccine 2003;21(25-26):3684-9.

[47] Kutzler MA, Weiner DB. Developing DNA vaccines that call to dendritic cells. J Clin Invest 2004;114(9):1241-4.

[48] Kim TW, Lee JH, He L, Boyd DA, Hung CF, Wu TC. DNA vaccines employing intracellular targeting strategies and a strategy to prolong dendritic cell life generate a higher number of $\mathrm{CD} 8+$ memory $\mathrm{T}$ cells and better long-term antitumor effects compared with a DNA prime-vaccinia boost regimen. Hum Gene Ther 2005;16(1):26-34 .

[49] Frauenschuh A, DeVico AL, Lim SP, Gallo RC, Garzino-Demo A. Differential polarization of immune responses by co-administration of antigens with chemokines. Vaccine 2004;23(4):54654.

[50] Hartley O, Offord RE. Engineering chemokines to develop optimized HIV inhibitors. Curr Protein Pept Sci 2005;6(3):207-19.

[51] Lederman MM, Veazey RS, Offord R, Mosier DE, Dufour J, Mefford M, et al. Prevention of vaginal SHIV transmission in rhesus macaques through inhibition of CCR5. Science 2004;306(5695):485-7.

[52] Restifo NP, Ying H, Hwang L, Leitner WW. The promise of nucleic acid vaccines. Gene Ther 2000;7(2):89-92.

[53] Scheerlinck JY. Genetic adjuvants for DNA vaccines. Vaccine 2001;19(17-19):2647-56.

[54] Shinoda K, Xin KQ, Kojima Y, Saha S, Okuda K, Okuda K. Robust HIV-specific immune responses were induced by DNA vaccine prime followed by attenuated recombinant vaccinia virus (LC16m8 strain) boost. Clin Immunol 2006;119(1):32-7.

[55] Sallusto F, Lanzavecchia A, Mackay CR. Chemokines and chemokine receptors in T-cell priming and Th1/Th2-mediated responses. Immunol Today 1998;19(12):568-74.

[56] Vecchi A, Massimiliano L, Ramponi S, Luini W, Bernasconi S, Bonecchi R, et al. Differential responsiveness to constitutive vs. inducible chemokines of immature and mature mouse dendritic cells. J Leukoc Biol 1999;66(3):489-94. 
[57] Fukada K, Sobao Y, Tomiyama H, Oka S, Takiguchi M. Functional expression of the chemokine receptor CCR5 on virus epitope-specific memory and effector CD8+ T cells. J Immunol $2002 ; 168(5): 2225-32$.

[58] Molon B, Gri G, Bettella M, Gomez-Mouton C, Lanzavecchia A, Martinez AC, et al. T cell costimulation by chemokine receptors. Nat Immunol 2005;6(5):465-71.

[59] Aliberti J, Reis e Sousa C, Schito M, Hieny S, Wells T, Huffnagle GB, et al. CCR5 provides a signal for microbial induced production of IL-12 by CD8 alpha+ dendritic cells. Nat Immunol 2000;1(1):83-7. 


\section{Figure 1. Signaling activity of 1P7}

A. 1P7 is a CCR5 superagonist. Duplicate measurements of CCR5 agonist activity in response to various concentrations of CCL5 $(\mathbf{\square})$ and 1P7 (O) were made on Hela-P5L cells. Dose curves were fitted using Prism software (GraphPad). B. CCR5 internalization induced by CCL5 and 1P7. Steady-state levels of surface receptor on HEK-CCR5 cells were measured by flow cytometry after incubation with chemokines. Levels are expressed as percentages of that of the control (medium, no chemokine). Bar graphs show the mean \pm SD for two independent experiments performed under identical conditions. C. 1P7 has similar CCR5 binding affinity to native CCR5 ligands in a competition binding assay using ${ }^{125}$ I radiolabelled CCL3 on CHO-CCR5 cells. Each data point represents the mean \pm s.e.m. of quadruplicate determinations, expressed as a percentage of maximum specific binding (binding in the absence of competitor). D. 1P7 shows enhanced receptor selectivity over native CCR5 ligands. Measurements of CCR1 (upper panel) or CCR3 (lower panel) agonist activity at $300 \mathrm{nM}$ of CCL5, CCL3, CCL4 and 1P7 were made on HEK-CCR1 or HEKCCR3 cells respectively. At this concentration, 1P7 gave a maximum response closed to 5 and 30 $\%$ of that of CCL5 for CCR1 and CCR3 respectively

\section{Figure 2. Experimental setting}

Mice were immunized intramuscularly with $100 \mu \mathrm{g}$ of OVA plasmid + $100 \mu \mathrm{g}$ of CCL5-Ig, 1P7Ig or Ig plasmids at day 0. Each animal was injected subcutaneously in the right flank with $2.10^{4}$ E.G7-OVA tumor cells at day 30 .

Figure 3. Monitoring of OVA-specific CD8+ T cells following genetic vaccination with OVA and chemokine-Ig 
A. Representation of cytofluorometric analysis of fresh peripheral blood mononuclear cells from C57/B6 mice 15 days after co-injection with OVA plasmid and Ig, CCL5-Ig or 1P7-Ig plasmids. The percentages of circulating CD8+ T cells stained with the H-2Kb/OVA 257-264 tetramer are indicated for the indicated adjuvant groups B. Monitoring of OVA-specific CD8+ T cells on day 15 in wild type C57/B6 mice injected with indicated chemokine-Ig plasmids alone (circles, $\mathrm{n}=12$ in each group) or co-injected with OVA plasmid plus Ig plasmid (open triangles, $\mathrm{n}=30$ ), CCL5Ig plasmid (grey triangles, $\mathrm{n}=29$ ) or 1P7-Ig plasmid (black triangles, $\mathrm{n}=32$ ). C57/B6 CCR5 KO $\left(\mathrm{CCR}^{--}\right)$mice are co-injected as above with OVA plasmid and indicated chemokine-Ig plasmids (squares, $\mathrm{n}=7$ in each group). Comparisons are made using the Student $t$ test.

Figure 4. In vivo evaluation of cytotoxic activity after DNA vaccination Mice were injected as above with either OVA, Ig or chemokine-Ig plasmids alone or co-injected with OVA plasmid and chemokine-Ig plasmids ( $\mathrm{n}=3$ in each group). On day 15 after DNA vaccination, mice were intravenously injected with CFSE labeled target cells pulsed or unpulsed with the OVA peptide SIINFEKL. Cells were recovered $20 \mathrm{~h}$ after transfer and analyzed for CFSE intensity in a flow cytometric assay.

\section{Figure 5. Monitoring of tumor-challenged animals}

Inoculation of tumor cells was performed 30 days after DNA vaccination. Tumor development in each animal co-immunized with OVA plasmid + Ig, CCL5-Ig or 1P7-Ig plasmids was monitored until day 30 following tumor-challenge. A. Each vaccination group was injected with E.G7-OVA cells: Ig group ( $\mathrm{n}=14)$, CCL5-Ig ( $\mathrm{n}=13)$ and 1P7-Ig ( $\mathrm{n}=14)$ (NS: non significant). B. Monitoring of EL4 tumor size in animal groups described above ( $n=6$ in each group). C. Monitoring of tumor free mice following E.G7-OVA tumor challenge in mice co-immunized with OVA plasmid plus 
Ig, CCL5-Ig or 1P7-Ig plasmids. D. Proportion of antigen-specific CD8+ T cells in tumor-free (T) or tumor-bearing mice $(\mathrm{T}+)$. Percentage of OVA 257-264 specific CD8+ T cells were quantified on day 15 and tumor size were measured at day 24 after tumor challenge. 
A

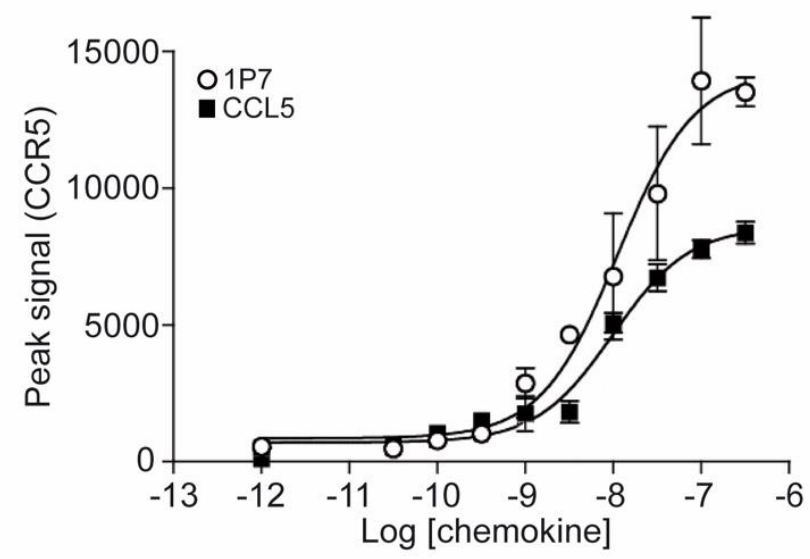

C

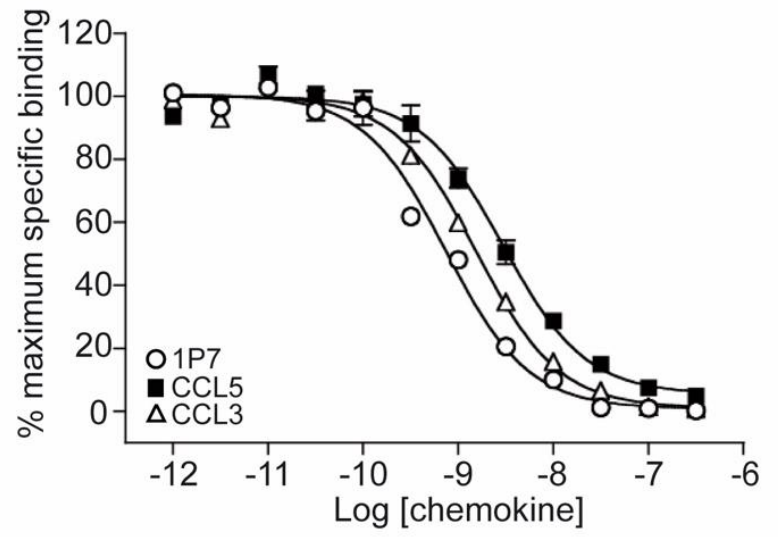

B

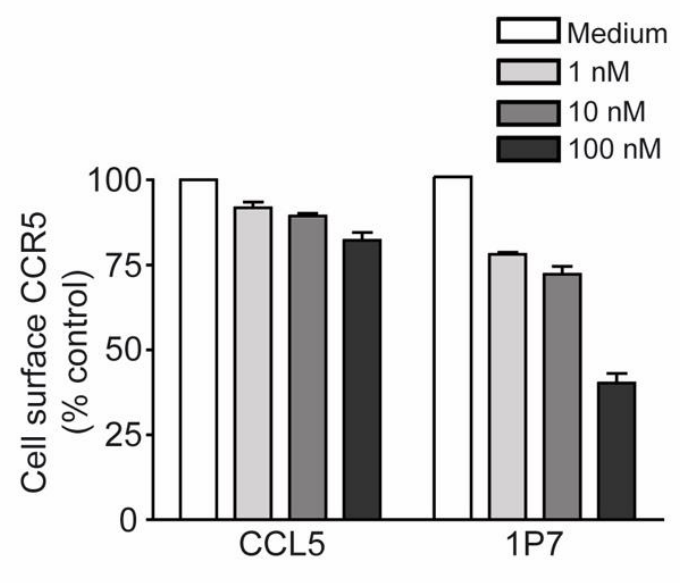

D
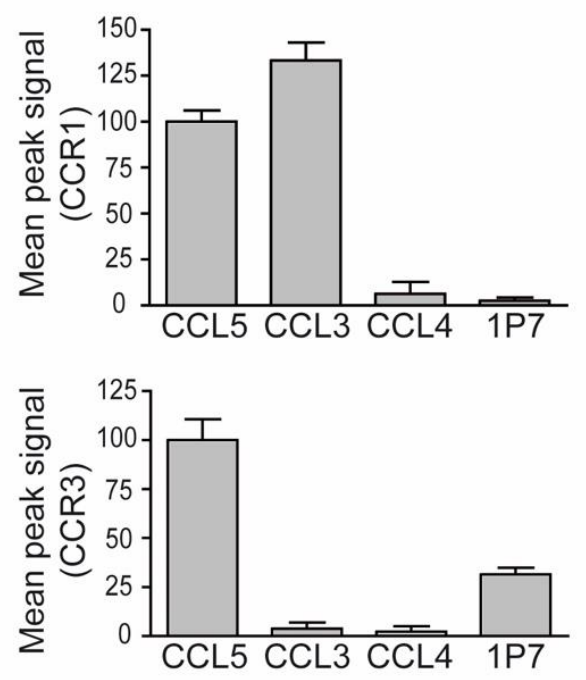

Dorgham et al., Figure 1 

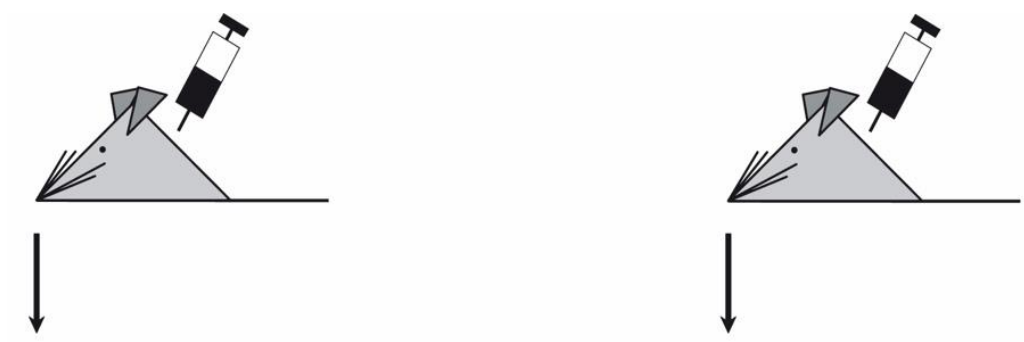

1

DNA vaccination

Tumor challenge

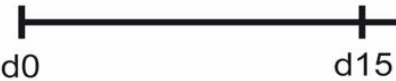

$\rightarrow+----------------1$

OVA +

CD8 T cells analysis $2.10^{4}$ EG7 cells d60

chemokine-lg analysis

Dorgham et al., Figure 2 
A

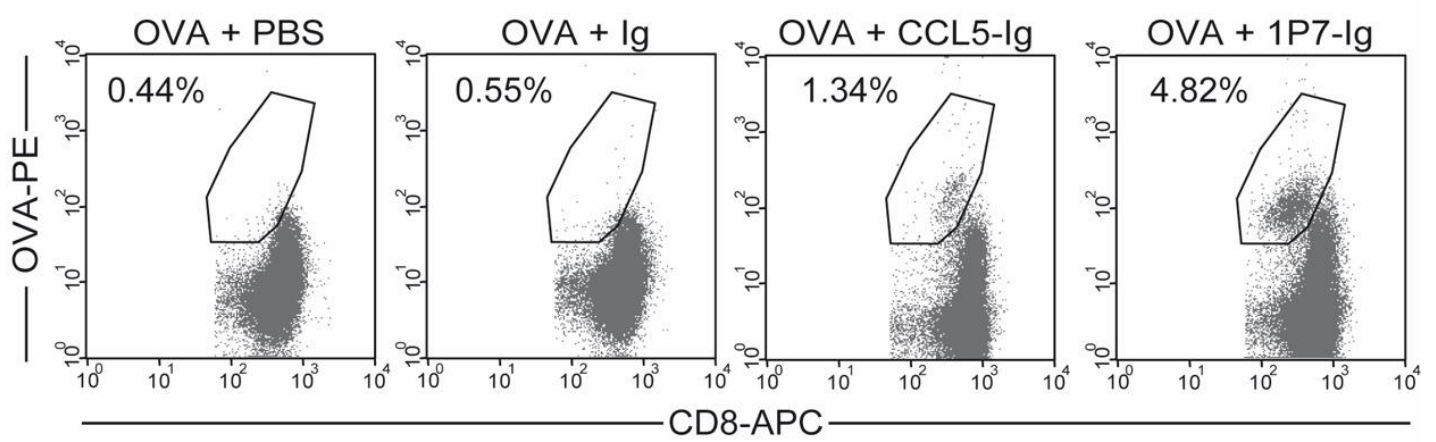

B

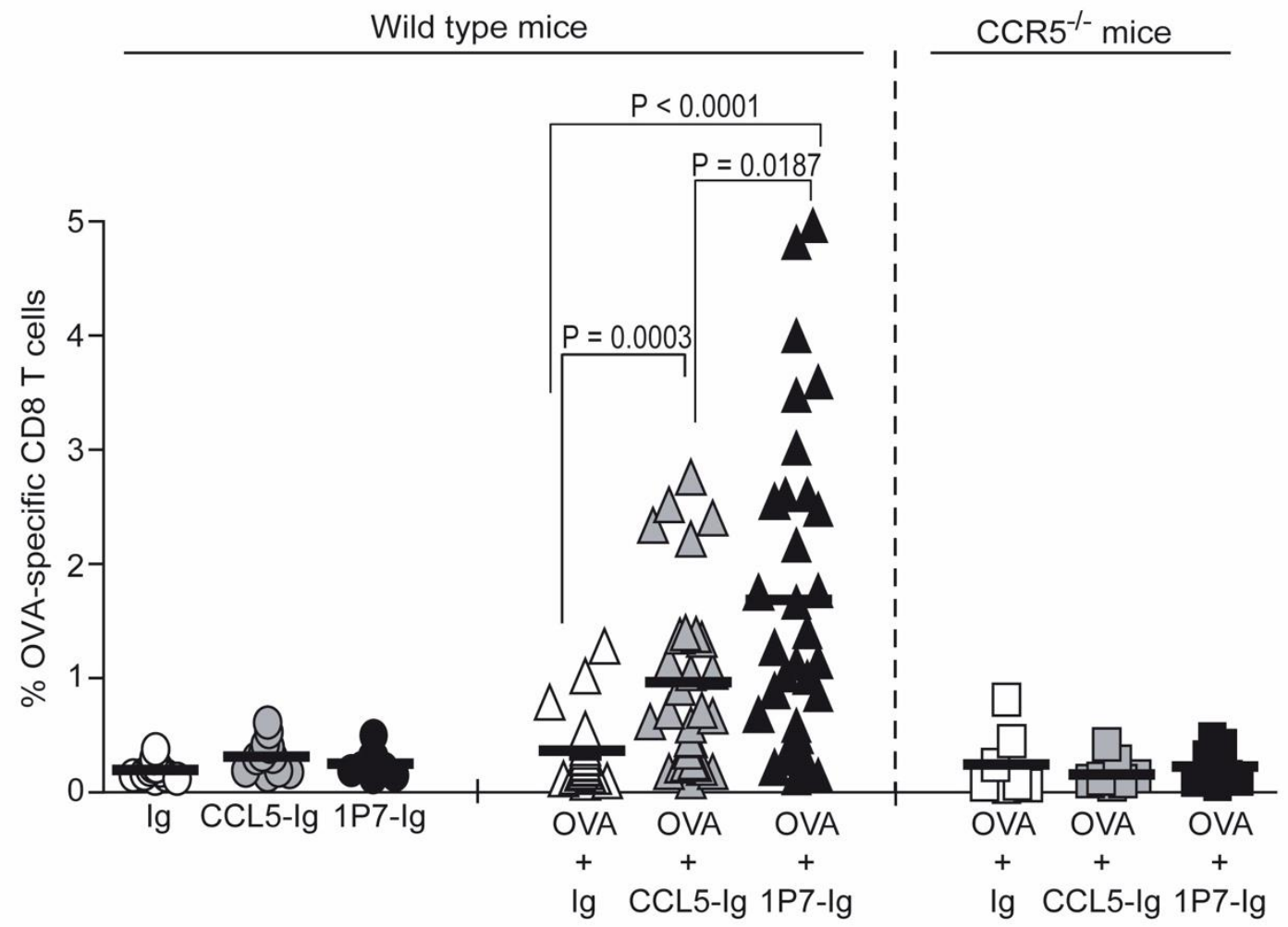

Dorgham et al., Figure 3 


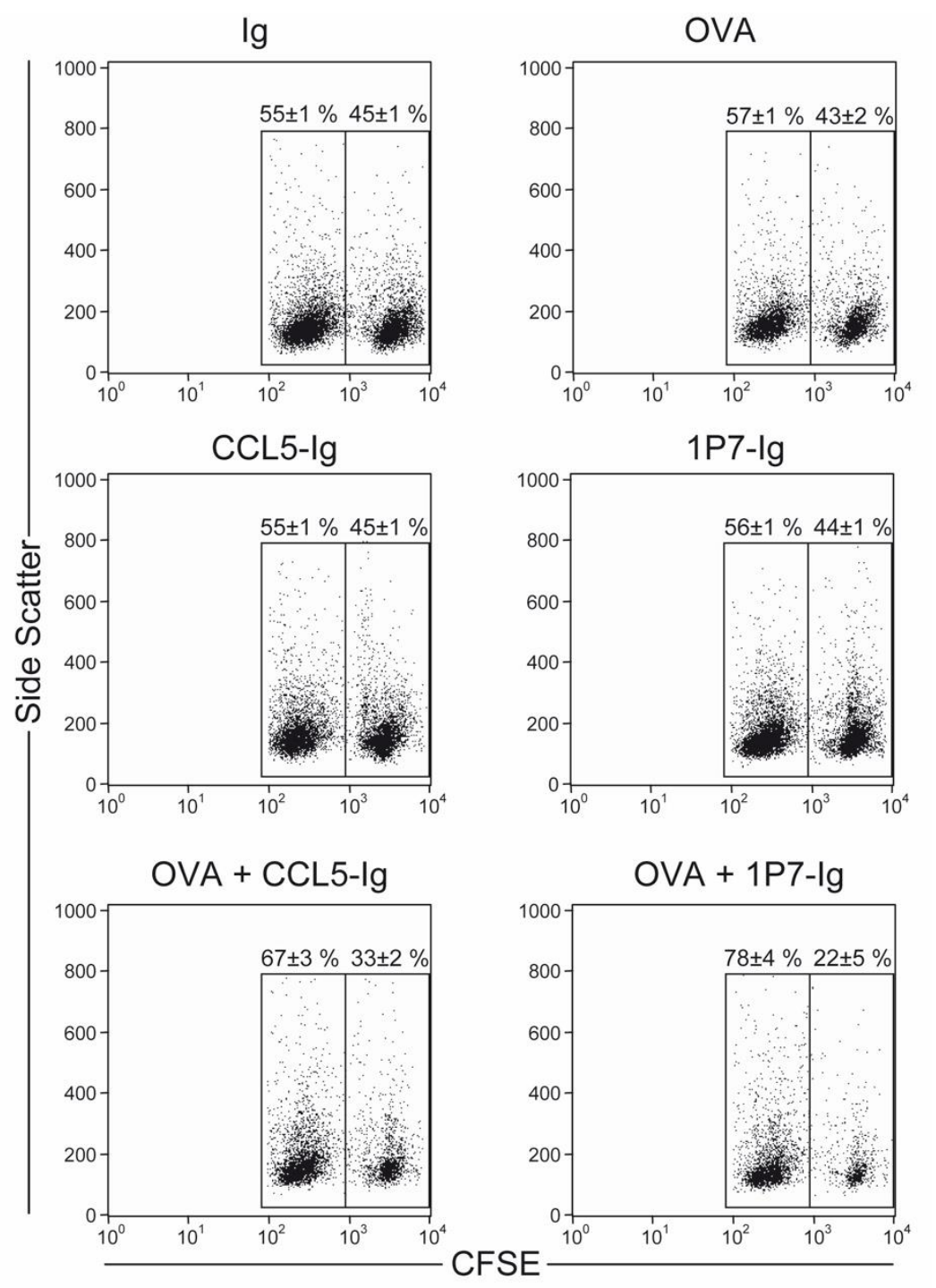

Dorgham et al., Figure 4 
A

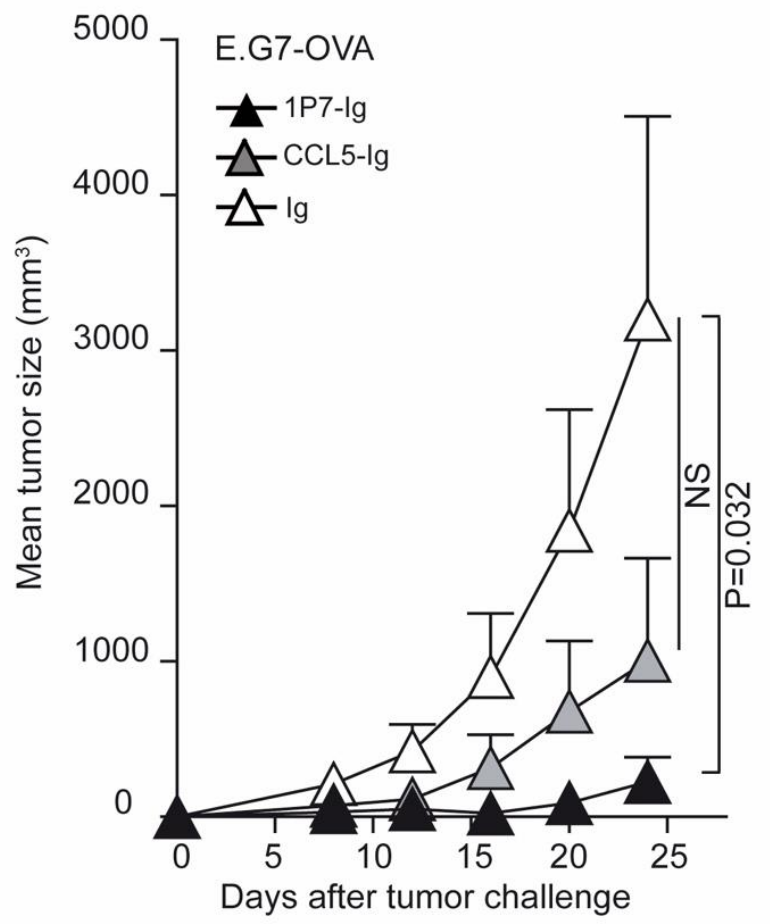

C

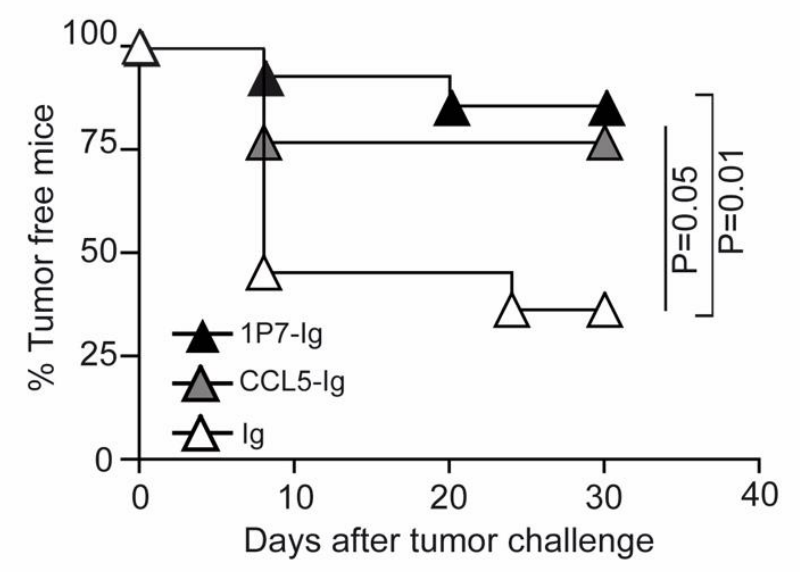

B

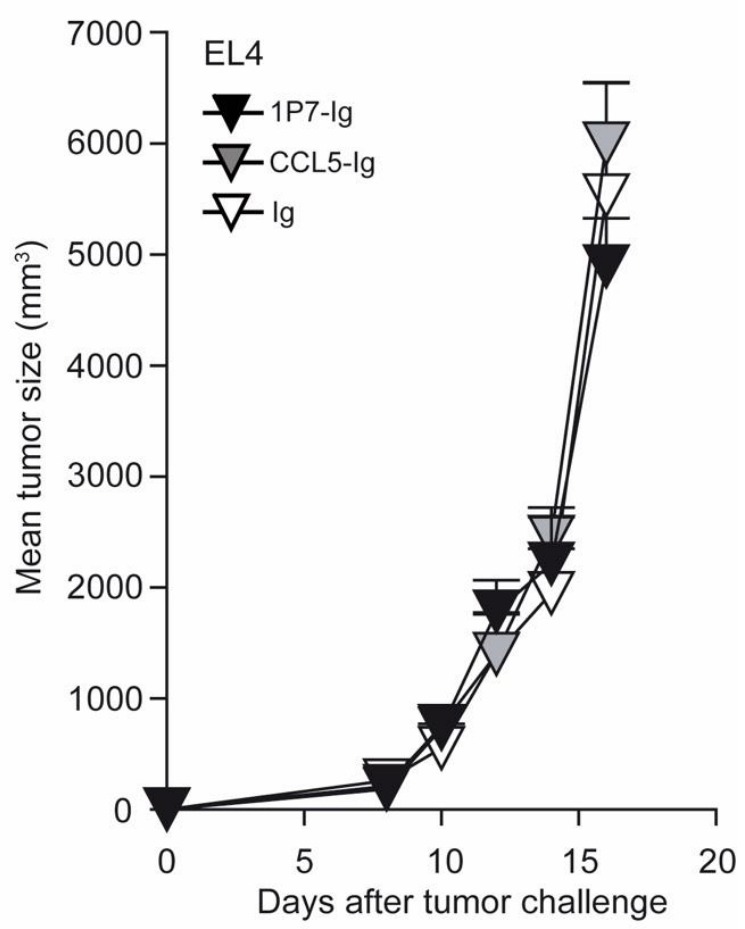

D

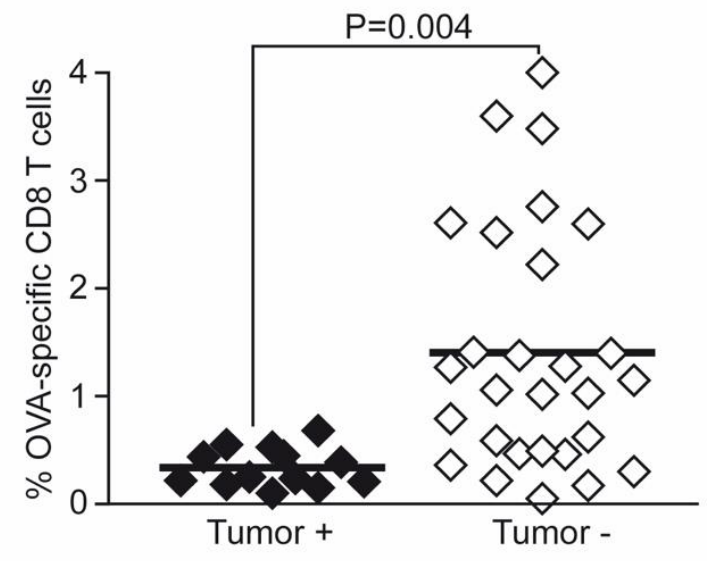

Dorgham et al., Figure 5 